\title{
Apontamentos acerca da busca pela felicidade na contemporaneidade
}

Findings on the search for happiness in contemporaneity Puntes acerca de la búsqueda por la felicidad en la contemporaneidad

Valbercley da Graça Almeida ${ }^{1}$ Cesar Augusto Veras ${ }^{2}$ Pedro Pereira Borges ${ }^{3}$

${ }^{1}$ Pós-graduando em Marketing Digital pela Faculdade Venda Nova do Imigrante (FAVENI). Graduado em Filosofia (licenciatura) pelo Centro Universitário Claretiano. E-mail: valbercleyalmeid@gmail.com, Orcid: http://orcid.org/0000-0003-4387-2207

${ }^{2}$ Pós-Graduado em Docência no Ensino Superior e bacharel em Filosofia pela Universidade Católica Dom Bosco (UCDB). Extensão universitária em Marketing Pessoal na UCDB. E-mail: semcesaraugusto@gmail.com, Orcid: http://orcid.org/0000-0003-3620-7559

${ }^{3}$ Doutor e mestre em Ciências Sociais pela Pontifícia Universidade Católica de São Paulo (PUC-SP). Graduado em Pedagogia e Filosofia pela Universidade Católica Dom Bosco (UCDB). Graduado em Teologia pelo Instituto Santo Tomás de Aquino de Belo Horizonte (Ista) e pela Università Pontificia Salesiana di Roma (UPS-Roma). Diretor-presidente da Fundação Dom Bosco. Professor no Programa de Pós-Graduação Mestrado e Doutorado em Desenvolvimento Local da UCDB.

E-mail: pobojari@uol.com.br, Orcid: http://orcid.org/0000-0001-9183-5051 
Resumo: A felicidade é considerada um tema bastante difundido, da Antiguidade ao presente. Refletir sobre ela faz-se extremamente necessário, visto que sobre a felicidade muito se incentiva desordenadamente, mas pouco se pensa. O objetivo principal deste estudo é propor uma reflexão sobre a busca pela felicidade, a fim de conduzir o leitor ao ponto de partida do caminho de conquista da própria felicidade. Pretende-se utilizar pesquisa bibliográfica a partir de obras disponibilizadas nos meios virtual e impresso, como metodologia para o cumprimento da referida proposta. Defronte aos objetivos, foi possível chegar a algumas considerações, delas são destacadas três: 1) Tal busca propriamente dita, sem antes verificar outras questões pertinentes, mostra-se ineficaz; 2) É inerente ao ser humano o desejo de uma felicidade duradoura, mesmo que aparentemente ela não exista; 3) A felicidade pode estar fundamentada na posse da sabedoria e no conhecimento do sentido; nessas duas coisas, a felicidade torna-se uma consequência.

Palavras-chave: felicidade; sentido; sabedoria; busca.

\begin{abstract}
Happiness is considered a very widespread theme, from antiquity to the present. Reflecting on it becomes extremely necessary since happiness is much encouraged in a disorderly way, but little is thought. The main objective of this study is to propose a reflection on the search for happiness, in order to lead the reader to the starting point of the path to the conquest of happiness. It is intended to use bibliographical research based on works made available in the virtual and printed media, as a methodology for compliance with said proposal. In front of the objectives, it was possible to arrive at some considerations, of which three are highlighted: 1) Such a search properly, without first checking other pertinent questions, is ineffective; 2) It is inherent to the human being the desire for a lasting happiness, even if apparently it does not exist; 3) Happiness can be based on the possession of wisdom and the knowledge of meaning; in these two things, happiness becomes a consequence.
\end{abstract}

Keywords: happiness; sense; wisdom; search.

Resumen: La felicidad es considerada un tema bastante difundido, desde la antigüedad al presente. Reflexionar sobre ella se hace extremadamente necesario, ya que sobre la felicidad mucho se alienta desordenadamente, pero poco se piensa. El objetivo principal de este estudio es proponer una reflexión sobre la búsqueda de la felicidad, a fin de conducir el lector al punto de partida del camino de conquista de la propia felicidad. Se pretende utilizar investigación bibliográfica a partir de obras disponibles en los medios virtuales e impresos, como metodología para el cumplimiento de la referida propuesta. En el caso de los objetivos, es posible llegar a algunas consideraciones, de ellas se destacan tres: 1) Tal búsqueda propiamente dicha, sin antes verificar otras cuestiones pertinentes, se muestra ineficaz; 2) Es inherente al ser humano el deseo de una felicidad duradera, aunque aparentemente no exista; 3) La felicidad puede estar fundamentada en la posesión de la sabiduría y en el conocimiento del sentido; en estas dos cosas, la felicidad se convierte en una consecuencia.

Palabras clave: felicidad; sentido; sabiduría; búsqueda. 


\section{INTRODUÇÃO}

A busca pela felicidade é um tema que perpassa por toda a história da humanidade, desde a pré-história até os dias de hoje. Durante vários séculos, este tema vem sendo discutido por filósofos, de modo particular, pelos filósofos da Grécia Antiga.

Na contemporaneidade, a busca pela felicidade é amplamente difundida e, com isso, muitas vezes, ela acaba sendo atropelada por uma enxurrada "pseudoespecialistas" e manuais que prometem levar a pessoa até a felicidade ou trazer a felicidade até a pessoa, mas que falham na gigantesca maioria das vezes. Diante disso, urge a necessidade de, a exemplo dos gregos antigos, parar um pouco sobre esse tema.

O presente trabalho se justiça à sociedade, pois a busca pela felicidade Ihe é inerente, visto que ela é algo intrínseco a todos os seres humanos e a estes é intrínseca tal busca. É também pertinente ao meio acadêmico, especialmente filosófico, pois este parece afastar-se de suas raízes gregas e, portanto, da reflexão sobre o tema proposto. Por fim, justifica-se a presente pesquisa a cada pessoa individualmente, pois o tema, como apontado acima, é algo inerente a todos e a cada um.

Não é intenção desta pesquisa colocar um ponto final, tampouco proclamar um dogma, mas o objetivo principal é refletir sobre a felicidade e, principalmente, sobre a busca por ela. Para tanto, foram organizados três objetivos específicos: examinar o conceito de felicidade e a busca por ela com Agostinho; buscar compreender como um ser humano enxerga sua própria existência dentro do campo de concentração; e, por fim, como um filósofo contemporâneo propõe a busca pela felicidade.

Para a realização deste trabalho, será utilizada uma pesquisa bibliográfica, por meio de obras disponíveis a todos, por intermédio dos meios impresso e virtual. Procurando melhor sistematizar o desenvolvimento do presente artigo, ele foi organizado em tópicos, a saber: 1) Introdução; 2) A busca do ser humano pela felicidade em Agostinho; Prisioneiro 119104 e a busca pelo sentido (Viktor E. Frankl); 3) A felicidade, desesperadamente (André Comte-Sponville); 4) Considerações. 


\section{A BUSCA DO SER HUMANO PELA FELICIDADE EM AGOSTINHO}

Desde a Antiguidade, observam-se concepções materialistas ${ }^{1}$ e mundanas a respeito da conquista da felicidade - aquelas coisas que o homem deseja enquanto objeto de possível felicidade, que não estejam ligadas com a matéria ou tenham ligação mínima com essa; por exemplo, relações sexuais. Aqueles que são adeptos dessas correntes defendem a felicidade como sendo o prazer e o gozo de determinados "objetos" do querer humano, tais como: relações sexuais, a sensação causada devido ao uso de alguma droga (entorpecentes ou alcoólicas) ou, até mesmo, honra, glória, riqueza. Tais concepções de "felicidade" são combatidas por Sócrates, Platão e Aristóteles, visto que estes defendem a felicidade como o aperfeiçoamento enquanto homem até chegar a posse do chamado bem supremo. Nesse sentido, na releitura de Agostinho acerca de Aristóteles, aqueles que têm o prazer como objeto de busca são equiparados aos escravos e têm a vida qualificada como "digna de animais".

O bispo de Hipona expressará em sua obra De retractiones ${ }^{2}$ que a "vida futura" é aquela única que merece ser chamada de vida feliz. Em A trindade, reconsidera a máxima de Terêncio - querer o que se pode, quando não se pode o que se quer - classificando-a como felicidade ridícula, alegando ser cômodo querer apenas aquilo que se pode fazer. Ora, para ele - Agostinho -, a felicidade somente é possível com a imortalidade, e essa em Deus. Já na obra De beata vita ${ }^{3}$, Agostinho de Hipona desenvolve a sua tese de que "a vida feliz consiste no perfeito conhecimento de Deus" (AGOSTINHO, 1998b, p. 115), entendendo que a felicidade consiste em algo absoluto e perfeito

\footnotetext{
${ }^{1} \mathrm{O}$ termo materialista aqui não segue o sentido cunhado no século XIX por Karl Marx e Friedrich Engels, mas sim em referência aos bens materiais que o homem coloca como objeto de desejo.

${ }^{2}$ De retractiones é a obra escrita por Agostinho na qual ele faz uma revisão de algumas obras escritas em anos anteriores, bem como seu posicionamento acerca de determinados assuntos já expostos em anos anteriores de sua vida.

${ }^{3}$ De beata vita - em português, "A vida feliz" - é um diálogo ocorrido em comemoração por ocasião do 32 ำ natalício de Agostinho, ao qual se reúne com alguns amigos, discípulos e sua mãe, Mônica, e nele faz um diálogo a respeito de um tema apreciado na Antiguidade: Felicidade.
} 
(Deus), e não em alguma coisa criada, dotada de imperfeições, inclusive a da temporalidade.

O ser humano, no transcorrer de sua existência, almeja alcançar a felicidade. Refletindo acerca de tal indagação existencial, Agostinho acredita na possibilidade de viver a felicidade por meio da esperança, isto é, esperança de um dia conhecer profunda e interiormente Deus e, com Ele, viver pela eternidade. Concomitante a isso, salienta Agostinho (1998b, p. 115):

[...] a perfeita plenitude das almas, a qual torna a vida feliz, consiste em conhecer piedosa e perfeitamente: - por quem somos guiados até a Verdade (o Pai); - e qual Verdade gozamos (o Filho); - e por qual vínculo estamos unidos à Suma Medida (o Espírito Santo) (cf. IV,35). A felicidade está centrada no conhecimento da Verdade na interioridade da alma. Conhecimento que, ao mesmo tempo, é posse e gozo de Deus: "feliz quem possui Deus". A sabedoria que nos dá a felicidade consiste em fruir, deleitar-se em Deus, a Verdade infinita, nosso Bem Supremo e Imutável. Nossa perfeição moral e nossa felicidade consistem em conhecer e amar este Sumo Bem.

Nesse sentido, Agostinho proporá, por meio de metáforas, que existem três tipos de navegantes. O primeiro é o "[...] daqueles que, tendo chegado à idade em que a razão domina, afastam-se da terra, mas não demasiadamente" (AGOSTINHO, 1998b, p. 118), isto é, são aqueles que não vão muito longe em direção ao "porto da Filosofia - único ponto de acesso [...] à terra firme da vida feliz" (AGOSTINHO, 1998b, p. 117), mas fixam-se em um lugar tranquilo, já afastado do cais de onde saiu, mas que ainda não é aquele porto seguro supracitado, ou seja, um ponto de ancoragem "no meio do caminho", ainda à vista daqueles que ficaram para trás e de onde buscam trazer os demais para perto de si - procuram manifestar sinais luminosos que têm por objetivo incutir o desejo nos concidadãos de seguirem àqueles -, levando si próprios e os demais a uma espécie de acomodação.

Quanto ao segundo tipo de navegantes, estes são formados por aqueles que são iludidos pelo aspecto astucioso do $\mathrm{mar}^{4}$, arriscam-se indo

${ }^{4} \mathrm{O}$ "mar" é o caminho que o navegante, baseado no texto Agostinho em De beata vita, tem de percorrer do cais, de onde o navegante saiu (de sua nação), a fim de chegar ao porto seguro da Filosofia, onde se encontrará a felicidade. Tal caminho é repleto de obstáculos, e estes, por vezes, fazem com que os navegantes não consigam atracar no 
longe, mas acabam perdendo-se na miséria da frustração gerada por não ter conseguido cumprir o objetivo inicialmente proposto, o que faz com que esperem aflitos por uma tempestade, isto é, por algum grande acontecimento (ou uma série desses) que os leve novamente a um lugar seguro ${ }^{5}$; alguns acabam conseguindo tamanha façanha, enquanto outros não são agraciados da mesma forma.

Já o terceiro tipo de navegantes é considerado o equilíbrio entre os dois anteriores, ou seja, desde a adolescência eles são balançados pelo mar, porém sempre se lembram do porto de onde saíram; esse grupo de navegantes, ao sofrer alguma infelicidade em meio a prosperidades efêmeras, retorna ao porto seguro de onde saiu. Assim, eles apresentam, então, as fases de sua própria navegação em busca da felicidade.

Na primeira fase de sua própria navegação, Agostinho inicialmente deixou-se ser conquistado pelo amor à filosofia. Contudo admite também que foi induzido ao erro, pois acabou retendo seu espírito longe da investigação que o levaria além. A segunda fase - caracterizada pelo abandono de Agostinho aos maniqueus ${ }^{6}$ e sua adesão aos acadêmicos ${ }^{7}$ - faz com que Agostinho seja balançado de um lado para outro, devido aos questionamentos a que ele mesmo se propõe. Por fim, tendo retornado ao porto seguro de onde saíra, Agostinho chega à conclusão de que, após sermões de seu bispo e conversas com Teodoro, qualquer ideia que tenha de matéria ao se referir a Deus deve ser excluída, isto porque a Deus cabe a imortalidade e perfeição, o que não está em sintonia com qualquer coisa criada, visto que qualquer coisa criada está passível de imperfeições e, até mesmo, de findar-se ora ou outra.

porto de destino ou desistam de navegar, procurando, assim, um lugar tranquilo, o mais próximo possível, para que possam atracar.

${ }^{5}$ Nesse contexto, "lugar seguro", para Agostinho, são as alegrias firmes e seguras.

${ }^{6}$ Seguidores do Maniqueísmo. Segundo Correia (2013, p. 1), “O maniqueísmo, assim como outros gnosticismos, buscava explicar a origem do mal no mundo. Para tanto, pensava no mundo de forma dualista sendo gerido por dois princípios, um bom e outro mal, que estavam em luta. Tudo era explicado pela oposição entre os princípios, desde a criação do mundo (cosmogonia), a criação do homem, a moral e o juízo final.".

${ }^{7}$ Seita filosófica que, por ter como princípio a dúvida universal, gera indiferença e ceticismo entre seus seguidores. 
A exclusão de qualquer ideia material ao se referir a Deus deve também ser feita, segundo Agostinho, em relação à alma, pois segundo o bispo de Hipona ela é a realidade mais próxima de Deus; ou seja, como Deus é imaterial, ela (alma) também é imaterial, isto é, não tem matéria. É possível perceber que Agostinho também passa por todas as fases da navegação em busca do "porto tranquilo" da felicidade, cometendo, a seu modo, os equívocos humanos inerentes à busca. Verifica-se também que, comprometido com o seu objetivo, recuando quando necessário e avançando quando possível, o filósofo vislumbra a terra firme (da felicidade) que tanto almeja.

Agostinho constata, com base na leitura dos neoplatônicos, que o ser humano é constituído de corpo e alma, sendo que a alma é imortal. Nessa perspectiva, o corpo físico está sujeito a sucumbir pela falta de alimentos que o nutra, e também a alma pode definhar, mas, nesse caso, devido à fome causada pela falta de conhecimentos. Em contraposto à alma nutrida (dos sábios), está a dos "famintos", ou seja, dos ignorantes, cuja única necessidade iminente é a de buscar o alimento ${ }^{8}$ necessário. É sabido e deixado às claras durante o diálogo que tanto para o corpo quanto para a alma são necessários alimentos; contudo fica evidenciado que, para ambos, existem aqueles alimentos que são salutares e aqueles que são maléficos, necessitando, assim, que o indivíduo faça o discernimento sobre qual consumir.

A busca incessante acontece sempre que o motivo da felicidade de determinado indivíduo o deixa de ser, isto é, sempre que algo que faz com que aquele indivíduo sinta-se feliz - ganhar na loteria - deixa de fazê-lo feliz, sem quais forem os motivos; por exemplo: o findar do dinheiro ganho, não ver mais sentido naquela fortuna, talvez por não saber o que fazer após tê-la ganho, ou sempre que aquele outro já não se sente feliz com o que possuíra por último. Assim, emerge então a indagação acerca da durabilidade da felicidade. Isso porque, quando a felicidade está pautada em algo efêmero, isto é, em algo passageiro e sujeito a adversidades várias, pode-se dizer que, da mesma forma, essa felicidade também estará

\footnotetext{
${ }^{8}$ Alimento aqui não se refere aos alimentos materiais destinados ao corpo, mas sim ao alimento da alma que "é o conhecimento das coisas e da ciência" (AGOSTINHO, 1998b, p. 126).
} 
sujeita a findar-se. Agostinho aponta para a necessidade de o ser humano buscar algo duradouro como motivação da felicidade, visto que, assim, ela também o será. Agostinho não afirma que quem possui o que deseja não é feliz, mas sim que a felicidade desse não é absoluta, visto que pode perder aquilo que possui e gosta, devido a uma eventualidade qualquer. Desse modo, é necessário desejar e buscar, para ser plenamente feliz, algo que seja não somente duradouro, mas que não exista a possibilidade de o deixar de ter. Contudo não é necessário o completo desprezo dos bens materiais, mas sim é salutar a posse e o uso moderados de tais. Sobre isso, aponta Agostinho (1998a, p. 37-8):

Nada mais me interessa delas ${ }^{9}$ senão, se acontecer que eu chegue a possuí-las, apenas o necessário sustento e o seu uso liberal. [...] as riquezas não devem ser de modo algum ambicionadas, mas sim, se advierem, devem ser administradas com muita retidão e cautela. Acho que não existe nada que possa abater o ânimo viril mais que as carícias femininas e o contato dos corpos, sem o qual não se pode ter esposa. Por isso, se é obrigação do sábio dedicar-se aos filhos (o que ainda não constatei), e só por isso ele coabita, isso parece-me que é mais de se admirar, mas de modo algum imitar; pois há maior perigo em tentar fazer que felicidade em ser capaz de fazê-lo. Pelo que acho que minha decisão de não desejar nem procurar esposa nem casar-me foi uma decisão suficiente, justa e útil, pela liberdade de minha alma. Em nada me atraem aqueles alimentos que decidi não comer. Mas confesso que sinto prazer naqueles que não eliminei; contudo, de tal modo que não há nenhum apego interno quando são retirados depois de vistos ou saboreados.

Concomitante a isso, ao explicar o modo de atingir esse estado de felicidade duradoura, Agostinho compreende que aquele que tem a Deus é feliz, pois, sendo Deus eterno e imutável, está livre de qualquer adversidade temporal ou que do tempo provenha. Aquele que busca a felicidade é porque ainda não a possui, e assim está sujeito ao tempo. Ele o faz já tendo uma definição preestabelecida de felicidade - possuir determinada coisa, estar com determinada pessoa, fazer determinada viagem etc. -, porém, como posto anteriormente, tais coisas estão sujeitas ao tempo. Também o

\footnotetext{
${ }^{9}$ Sobre as riquezas.
} 
indivíduo que busca a felicidade está sujeito ao tempo, visto que é dotado de matéria corpórea. Ora, o indivíduo que busca a felicidade não a busca refletindo sobre a durabilidade dela, visto que no interior do indivíduo há o desejo de que ela seja permanente. Contraposto a isso está a posse de Deus, que, sendo atemporal, faz com que a felicidade daquele que $O$ possua seja duradoura.

Desse modo, para ser plenamente feliz, o ser humano necessita buscar algo duradouro, para que a própria felicidade seja também duradoura. Em qualquer coisa criada - sujeitas às mais diversas intempéries -, não se pode encontrar a verdadeira e plena felicidade, ou seja, deve-se buscar ter algo que não seja criado e que esteja livre de quaisquer adversidades. Assim, Agostinho acredita que o que está livre de quaisquer modificações é Deus. No plano de vida material, é possível apenas ser feliz parcialmente - no entendimento do bispo de Hipona -, mesmo que buscando ter Deus, visto a temporalidade humana e a atemporalidade divina, isto é, pelo fato de que o indivíduo está sujeito ao tempo (nasceu, vive e morrerá) e pelo fato de Deus estar fora do tempo (não nasceu, quanto menos morrerá). PossuíLo em plenitude é, portanto, ser plenamente feliz; porém isso apenas será possível após a morte da vida terrena e "nascimento" para a vida eterna (vida pós-terrena).

\section{PRISIONEIRO N. 119104 E A BUSCA PELO SENTIDO}

Durante o Holocausto", grupos eram considerados como "raças inferiores" e que supostamente ameaçavam a superioridade da raça alemã. Tendo como objetivo garantir tal superioridade, o governo nazista procurou extirpar todos os inferiores. Para isso, as tropas nazistas ${ }^{11}$ torturavam e matavam sem nenhum escrúpulo, sob o comando do próprio Hitler e

\footnotetext{
${ }^{10}$ Tendo como base o exposto no site do Museu Memorial do Holocausto dos EUA, "Holocausto é uma palavra de origem grega que significa 'sacrifício pelo fogo'". Foi uma perseguição que promoveu um verdadeiro genocídio, especialmente entre o povo judeu, que era a maioria dos habitantes nos países que o partido nazista dominaria.

${ }^{11}$ As Tropas de Proteção (SS) foram a força liderada por Hitler após a queda do fundador da Seção de Assalto (SA). Posteriormente, em 1940, passou a ser conhecida oficialmente como "Waffen-SS" (COSTA, 2013, p. 32).
} 
de Heinrich Luitpold Himmler ${ }^{12}$. O psicólogo austríaco Viktor Emil Frankl, levado para o campo de concentração em Auschwitz por ser judeu, teve sua vida totalmente destruída. Frankl não se deixou abater pela sequência de desastres, mas encontrou naquela horripilante situação a oportunidade de viver ele próprio a busca pelo sentido.

Assim, Frankl buscou responder à pergunta acerca do modo que um prisioneiro médico refletia a vida cotidiana dentro do campo de concentração. Os campos de concentração propiciavam aos que ali eram aprisionados torturas que jamais esqueceriam - caso fossem libertados algum dia - e mortes cruéis. Para sobreviver nesse ambiente, além de trabalhar excessivamente nas condições mais precárias possíveis e sem reclamar, era necessário um milagre divino - para os que acreditam - ou simplesmente sorte. Lutava-se diariamente, porém de forma velada, por tudo quanto se pode imaginar, até mesmo para ter o absolutamente indispensável a fim de não morrer por conta da desnutrição. Cada indivíduo aprisionado em Auschwitz, ou em campos menores, lutava pela própria vida, por seus próprios interesses e pelos interesses daqueles que faziam parte do grupo íntimo de amigos, embora, por vezes, até os membros desses pequenos grupos eram traídos em nome da "sobrevivência". Contudo existia outra maneira de não morrer e de não ser torturado lá dentro, que era tornando-se "capo", isto é, uma espécie de ajudante dos guardas; este, mesmo sendo prisioneiro no campo de concentração, fazia muitas vezes o papel ${ }^{13}$ dos guardas junto aos demais prisioneiros.

Para tornar-se um capo, era necessário se sujeitar ao papel de vigiar e torturar os demais prisioneiros e, por vezes, eles eram piores que os guardas. Caso se esquivassem do que era esperado de um capo, ou não o fizessem a contento, eram imediatamente rebaixados. Para alguns, era questão de sobrevivência, embora não se possa excluir a possibilidade de terem existido aqueles que o faziam por prazer ou que pegaram gosto pela função com o

12 Nomeado por Hitler como "Comandante do Exército de Reserva e General Plenipotenciário para toda a administração do Reich" (COSTA, 2013, p. 31, nota de rodapé 84).

${ }^{13}$ Papel aqui refere-se às funções dos guardas, tais como: comandar um determinado grupo de prisioneiros no trabalho diário, "disciplinar" determinado prisioneiro quando algo não estivesse a contento ou descumprisse alguma ordem dada. 
passar do tempo, visto que eram bem recompensados pelos serviços que prestavam: tinham cupons-prêmio ${ }^{14}$ garantidos, os quais podiam trocar por cigarros ou por melhor alimentação, além de não precisar trabalhar da mesma forma que acontecia com os menos afortunados. Aqueles que fumavam eram os que conseguiam fazer parte desse seleto grupo; todavia, quando se via algum prisioneiro comum fumando, em vez de trocar aquele cigarro por sopa, já se sabia que este tinha perdido a esperança de melhorar a própria situação ou até mesmo de viver, ou seja, significava que não tinha mais vontade de continuar lutando por tudo e desejava aproveitar tanto quanto pudesse os seus últimos dias de vida.

Vale ressaltar que, no campo de concentração, lutava-se também para não ser selecionado a ser transportado para outros campos de concentração, pois se acreditava veementemente que, na verdade, esses eram levados para câmaras de gás, com a finalidade de serem mortos. Cada prisioneiro era identificado por um número ${ }^{15}$, não mais que isso, e quando se queria selecionar uma quantidade de prisioneiros a serem levados para a câmara ou para o crematório, via-se geralmente os que estavam doentes ou mais enfraquecidos e, no dia da "transferência", esses eram chamados pelos números. Sendo assim, era relativamente fácil burlar tal sistema e trocar de número com outro prisioneiro. Contudo aquele que conseguia tal feito sabia que outro seria levado em seu lugar, pois era necessário que a locomoção saísse com determinado número de prisioneiros. Observa-se que tal dinâmica com que as coisas aconteciam não permitia que muitos deles refletissem sobre ser certo ou errado tal atitude de trocar de lugar com outra pessoa. Em outros termos, cada prisioneiro era apenas um número e, sendo assim, não havia muito escrúpulo em fazer com que outro "número" fosse levado.

A primeira fase é caracterizada pelo choque causado pelo novo contexto em que estão sendo inseridos. Os novos prisioneiros (independentemente

\footnotetext{
${ }^{14}$ Os campos de concentração em Auschwitz sediam os prisioneiros para firmas de construção e, por cada prisioneiro, a firma tinha de pagar ao Campo de Concentração determinada quantia. Esses cupons eram a forma de "recompensar" determinado prisioneiro por serviços extras prestados, sendo que muitos desses serviços proporcionavam perigo à vida do próprio prisioneiro.

${ }^{15}$ O Dr. Viktor Emil Frankl era identificado pelo n. 119104.
} 
do campo de concentração para o qual estão sendo inseridos) são imersos numa sequência de acontecimentos ${ }^{16}$ que causam cada vez mais espanto e horror, por serem cruéis e desumanos. Pode-se dizer que a primeira fase das reações psicológicas vividas pelo prisioneiro seja, por vezes, a mais difícil (se não sempre), visto que é nela que acontece uma verdadeira destruição da dignidade do indivíduo e a desconstrução dos conceitos que este traz consigo. Experienciando isso, Frankl bem resume o que se passa na psique do novo prisioneiro ao dizer: "Faço aquilo que representa o ápice de toda essa primeira fase de reações psicológicas: dou por encerrada toda minha vida até ali" (FRANKL, 1987, p. 16).

Passados alguns dias de puro choque com as atrocidades que acontecem no campo, o prisioneiro começa em sua vida a segunda fase, que Viktor Frankl denomina de apatia. Tal apatia se instala nos prisioneiros após alguns sentimentos começarem a se aglomerar no interior de cada um deles, a saber: saudade de seus familiares; nojo de si próprio, devido aos trapos em que estão vestidos e os quais não se pode trocar; nojo do trabalho miserável com que os recém-chegados são imersos, entre outros. Influenciados por essa sobrecarga de acontecimentos degradantes, os sentimentos normais de cada um vão se esvaecendo lentamente e cotidianamente. Ao presenciarem obrigatoriamente algumas torturas contra outros encarcerados mais antigos, os neoprisioneiros são tomados por repulsa e horror.

Tendo se sujeitado a presenciar diversos acontecimentos e vivenciar diversos sentimentos, o prisioneiro, diante desses, acaba atingindo a capacidade de observar tais situações - de tortura e desumanidade -, por horas a fio, sem se deixar abater. Caso necessite de algum atendimento ambulatorial, o prisioneiro só o pode obter no período noturno, quando os trabalhos externos cessam, e até mesmo no ambulatório ocorre certa tortura psíquica. Relata Viktor (FRANKL, 1987, p. 21):

[...] quando ele mesmo, à noite, fica se espremendo no ambulatório na esperança de receber dois dias de "repouso", por causa de suas

${ }^{16}$ São alguns dos acontecimentos que causam tal choque da primeira fase: descobrirem o verdadeiro local para onde estão indo, a primeira seleção (que separava os homens das mulheres e esses daqueles que já seriam destinados a serem mortos logo no início), desinfecção, as primeiras torturas. 
lesões ou de seu edema, ou por causa de sua febre, de sorte que não necessita sair para o trabalho durante esses dois dias, não se deixa perturbar ao ver um menino de uns doze anos, para o qual não mais havia calçados no campo e que por isso fora obrigado a ficar por horas a fio de pés descalços na neve, prestando serviços externos durante o dia. Os dedos dos pés do menino estão crestados de frio, e o médico do ambulatório arranca com a pinça os tocos necróticos e enegrecidos de suas articulações. O nojo, o horror, o compadecimento, a revolta, tudo isso nosso observador já não pode sentir nesse momento.

Diante disso, a apatia é tamanha em meio aos prisioneiros que nem se chega mais a espantar-se com a morte de algum companheiro ou com o modo como lhe é subtraído o restante de seus poucos e miseráveis pertences. Também não causa mais nem um pingo de comoção o modo como os cadáveres são retirados do barracão e deixados ao relento, até que em outro momento os próprios prisioneiros os tirem dali e deem outro destino estipulado. A dor física causada pelos espancamentos ou pelo excesso de trabalho e falta de nutrição é ainda menor do que a dor psicológica, motivada pela revolta ante a injustiça vivenciada a todo momento; vai a uma dimensão mais profunda do ser humano, pois vê-se a dignidade e o próprio ser humano ser reduzido a nada. Contudo a apatia não é algo tão ruim, pois serve como defesa da psique, fazendo com que a pessoa apenas passe a perceber a realidade que a envolve.

Concomitante a isso, até mesmo o sentimento de desejo sexual é extirpado, involuntariamente, dos prisioneiros que nem sequer sonham com quaisquer relações. Um fator muito importante na falta de desejo sexual nos prisioneiros é a desnutrição. A falta de nutrição faz com que o instinto do prisioneiro não pense em outra coisa senão buscar alimentar-se, isto é, o primeiro plano de consciência deixa de lado todos os demais pensamentos e instintos, para buscar maneiras de sanar a fome extrema. Nada do que aqueles miseráveis prisioneiros tinham restou, nem mesmo em relação aos desejos sexuais. Pensa-se, então, por que não se suicidam logo, abreviando assim tamanho sofrimento? A esta a resposta é basicamente a mesma: esperança.

Faltando poucos meses antes da libertação, aconteceu um episódio entre Viktor e um companheiro que melhorou drasticamente o modo como 
o psicólogo passou a viver o seu cotidiano. O episódio consistiu basicamente na seguinte frase do companheiro de Viktor: "Se nossas esposas nos vissem agora...! Tomara que estejam passando melhor no campo de concentração em que estão. Espero que não tenham ideia do que estamos passando" (FRANKL, 1987, p. 31), somado à visão que o autor teve de sua esposa ${ }^{17}$. Tal comentário desencadeou uma sensação de liberdade na mente do prisioneiro 119104, que nem os capos nem os guardas seriam capazes de retirar dele. Essa liberdade consiste no diálogo intelectual ${ }^{18}$ - este acontece apenas na mente de Viktor, com uma imagem criada também por essa -, com sua esposa. Porém, se tal imagem é real ou não, não importa. Se soubesse naquele momento que ela estava morta, não lhe faria diferença. Isso porque o amor

[...] está ligado a tal ponto à essência espiritual da pessoa amada, a seu 'ser assim' (nas palavras dos filósofos) que a sua 'presença' e seu 'estar aqui comigo' podem ser reais sem sua existência física em si e independentemente de seu estar com vida (FRANKL, 1987, p. 32).

Esse colóquio, que acontece não poucas vezes, é um refrigério para Viktor e, com isso, ao voltar-se para dentro de si, é mais um motivo para sobreviver a cada humilhação, enquanto aguarda pelo fim de todo aquele martírio.

Não obstante as diversas circunstâncias e situações vivenciadas pelos prisioneiros no campo de concentração, Frankl afirma existir a liberdade interior - geistig - do espírito humano, isto é, a liberdade do "eu frente ao meio ambiente, mesmo nessa situação de coação aparentemente absoluta, tanto exterior como interior" (FRANKL, 1987, p. 50). Essa liberdade é apenas um resquício do que se tem fora daquele meio em que estão vivendo. Percebe-se que é possível reprimir a irritação causada pelas situações vividas no campo de concentração, bem como a superação da apatia, utilizando-se, para isso, de força interior e vontade próprias. Essas são possíveis graças à

\footnotetext{
${ }^{17}$ A esposa de Viktor Frankl também tinha ido para um campo de concentração destinado às mulheres. Viktor, porém, não tinha nenhuma notícia dela, não sabendo, inclusive, se estava viva ou morta.

${ }^{18}$ Este diálogo intelectual é um termo utilizado por Viktor Frankl no livro "Em busca de sentido" (1987, p. 32).
} 
decisão e firme propósito de não se deixar vencer perante aquelas dificuldades e, também, por não ter deixado acabar por completo a autoestima. Nesse sentido, salienta Frankl (1987, p. 50):

[...] mesmo que tenham sido poucos, não deixam de constituir prova de que no campo de concentração se pode privar a pessoa de tudo, menos da liberdade última de assumir uma atitude alternativa frente às condições dadas. E havia outra alternativa! A cada dia, a cada hora no campo de concentração havia milhares de oportunidades de concretizar esta decisão interior, uma decisão da pessoa contra ou a favor da sujeição aos poderes do ambiente que ameaçavam privá-la daquilo que é a sua característica mais intrínseca - sua liberdade - e que a induzem, com a renúncia à liberdade e à dignidade, a virar mero joguete e objeto das condições externas, deixando-se por elas cunhar um prisioneiro "típico" do campo de concentração.

Geralmente, os prisioneiros se preocupavam em saber se sobreviveriam ao campo de concentração; a esse questionamento, diziam não ter sentido algum tamanho sofrimento, caso não conseguissem sobreviver. Em contrapartida, Frankl se indagava se teria sentido no sofrimento, pois, caso contrário, não teria sentido escapar com vida dali, pois o sofrimento era quase insuportável, humanamente falando. A fim de não enlouquecer no campo de concentração, ao ponto de muito possivelmente dar cabo à própria vida, faz-se necessário ao prisioneiro buscar um sentido entre aquele caos. Sobre isso, é possível ver em "A busca de Deus e questionamentos sobre o sentido":

Existem três possibilidades básicas para encontrar o sentido, criar valores: A primeira, quando eu faço alguma coisa, crio algo; a segunda quando vivencio alguma coisa, quando eu amo, ou seja, dou alguma coisa para o mundo ou tomo alguma coisa do mundo; mas a terceira, quando já não houver mais nenhuma, por assim dizer, quando eu não consigo mudar uma situação, então depende de mim modelar também isto de forma útil ao transformar particularmente o sofrimento em um desempenho (FRANKL; LAPIDE, 2014, p. 121).

Estando os prisioneiros do campo de concentração recém-libertos, imaginava-se que, ao serem libertados, o sentimento que tomaria conta seria de alegria extrema pela conquista. Contudo não é bem assim que aconteceu com aqueles ex-prisioneiros. Durante todo o tempo em que 
foram prisioneiros naqueles campos de concentração, além de aprenderem a sobreviver com quase nada ou trabalhar com serviços pesadíssimos e sob condições extremas, aprendeu-se uma coisa muito peculiar, ou melhor dizendo, desaprendeu-se algo muito próprio do ser humano, isto é, eles desaprenderam o significado do termo alegria. Assim, era necessário, tendo passado pelos portões do campo de concentração rumo à liberdade factual, aprender tudo novamente: alegrar-se, encantar-se com as coisas belas, alimentar-se; e, em determinados casos, reaprender conceitos. Quando se tem a oportunidade de comer algo, faz-se com veracidade e eles falam, ao serem questionados, sobre o que se passou durante os anos dentro do campo, não com o objetivo de divulgar o que lá acontecera - até mesmo porque foram atrocidades inimagináveis -, mas porque há a necessidade de descarregar todo o contêiner de coisas que Ihes pesam às costas.

Os neolibertos careciam de assistência para os ajudar a descarregar tamanho peso, a fim de adaptar-se novamente a um mundo sem as atrocidades físicas e psicológicas que lhes foram acometidas nos campos de concentração. As reações que os neolibertos têm no pós-cárcere também merecem considerável atenção. Essa especial atenção se deve à possibilidade de aquele que sofreu tamanhas injustiças achar-se no direito de também praticar injustiças. Isso se dá pelo fato de, provavelmente, o conceito de justiça que o indivíduo tinha antes de ser aprisionado ter sido deturpado (às vezes, por completo) durante o tempo em que passou no campo de concentração; a esse ocorre, por vezes, que, por ter sofrido injustiças, o outro também o mereça.

Dessa forma, a busca pelo sentido é primordial para encontrar a felicidade. Frankl adere à terceira forma de encontrar o sentido, ou seja, modelou o sofrimento que passara durante o campo de concentração e não se deixou vencer pelos obstáculos constantes. É possível perceber que não é necessário ir além para encontrar o sentido do que se procura, mas que é possível encontrá-lo voltando-se para dentro de si. Quando essa jornada é dificultosa, às vezes é necessário lançar mão de subterfúgios a fim de vencê-la. Em consequência de ter encontrado o sentido, pode-se dizer calmamente que se encontrou a felicidade. 


\section{A FELICIDADE, DESESPERADAMENTE}

A busca da felicidade é algo inerente ao ser humano, ou seja, a todo e qualquer homo sapiens, e isso não pode ser negado. Diz Pascal apud Sponville (2001): "Todos os homens procuram ser felizes; isso não tem exceção... É esse o motivo de todas as ações de todos os homens, inclusive dos que vão se enforcar..." (SPONVILLE, 2001, p. 4). Para Sponville, é por meio da filosofia que se chegará à felicidade. Pautado em Epicuro, Sponville responde à pergunta "O que é a filosofia?" da seguinte forma: "[...] é uma prática discursiva [...] que tem a vida por objeto, a razão por meio e a felicidade por fim. Trata-se de pensar melhor para viver melhor" (SPONVILLE, 2001, p. 6). Assim, a felicidade é um tema bastante trabalhado pelos filósofos gregos. Estes apontam para a sabedoria como aquela que será capaz de encontrar "certa qualidade de felicidade" (SPONVILLE, 2001, p. 5), isto é, precisa-se buscar a felicidade por meio da sabedoria. Sobre o sentido de felicidade, aponta Tatiana Fagundes Audino (2015) em "O imperativo da felicidade na contemporaneidade":

[...] o sentido do que é concebido como felicidade ao longo da história não parece ser o mesmo. Na contemporaneidade, notamos que ela se apresenta como um imperativo colocado de saída: ser feliz, é preciso. É preciso agora e a qualquer preço. Sendo que, aquele que não consegue realizar este ideal está fadado a ser 'taxado' de deprimido e fracassado. O famoso loser $^{19}$ da cultura americana.

Comte-Sponville defende a busca por uma felicidade profunda, sendo possível por meio dos discursos e raciocínios, propostos pela prática discursiva filosófica, não sendo esta ilusória ou temporária. O filósofo apresenta o que ele chama de pílula da felicidade. Esta pílula consiste em um "remédio, uma espécie de ansiolítico e antidepressivo absoluto" (SPONVILLE, 2001, p. 7) que tem a capacidade de causar sensação de felicidade ao que a toma e continua causando-a enquanto o indivíduo consumir tal ansiolítico ${ }^{20}$. 0

\footnotetext{
${ }^{19}$ Em português: perdedor.

${ }^{20}$ Segundo site do Centro Brasileiro de Informações sobre Drogas Psicotrópicas (Cebrid), os ansiolíticos "São medicamentos que têm a propriedade de atuar sobre a ansiedade e tensão. [...] Também são utilizadas no tratamento de insônia e nesse caso também recebem o nome de drogas hipnóticas, isto é, que induzem sono".
} 
benefício de tal remédio é claro: a felicidade. Contudo essa pílula, embora não causasse nenhum tipo de dependência química, não seria eficaz, pois, segundo o próprio Sponville, para ser permanentemente feliz dever-se-ia tomar tal comprimido "todas as manhãs" (SPONVILLE, 2001, p. 7). Ora, em vez de o indivíduo estar ocupando seu tempo buscando a felicidade duradoura, consequência da detenção da sabedoria, ele está ocupado usufruindo os efeitos passageiros da droga que tomara pela manhã. Isto é, o indivíduo está, de certa forma, dependente do efeito de uma substância; não é feliz, mas vítima da dependência gerada pela necessidade de ter que tomar tal pílula diariamente.

Segundo Sponville, é feliz aquele que é sábio, ou seja, quem possuir sabedoria será feliz. Qualquer um, dotado de intelecto, tem grandes chances de ser feliz, tornando-se sábio. Ora, uma está intimamente ligada à outra, felicidade e sabedoria se complementam. Isto é, faz-se necessário possuir a sabedoria para que determinado indivíduo considere-se ou seja considerado uma pessoa feliz. A beatitude ${ }^{21}$ não é, portanto, uma fórmula matemática, capaz de fazer sábios felizes ou felizes sábios, à qual basta resolvê-la para achar uma felicidade/sabedoria pronta. Essa sabedoria, cuja posse é essencial à felicidade, exporá (SPONVILLE, 2002, p. 141-2):

O máximo de felicidade, no máximo de lucidez. É a vida boa, como diziam os gregos, mas uma vida que seja humana, em outras palavras, responsável e digna. [...] "Todo prazer é um bem", dizia Epicuro. Isso não quer dizer que todos eles mereçam ser buscados, nem mesmo que todos eles sejam aceitáveis. É preciso escolher portanto, comparar as vantagens e desvantagens, como dizia ainda Epicuro, em outras palavras, julgar. É para isso que serve a sabedoria. É também para isso que serve, e por isso mesmo, a filosofia.

$\mathrm{O}$ ato de filosofar deve trazer o indivíduo à felicidade. Mas, por ser a meta da filosofia, ela não está submetida a ela, ou seja, a filosofia não está submetida à felicidade, ou à sensação de breve felicidade. Para que o ato de filosofar seja efetivo, não basta pensar naquilo que transmite sensação de felicidade, porque essas podem ser apenas ilusões e, como tais, não levam

\footnotetext{
${ }^{21}$ Termo definido por Agostinho (apud SPONVILLE, 2001, p. 7) como "a alegria que nasce da verdade". Sponville utiliza da definição de Agostinho para designar a "felicidade do sábio".
} 
a pessoa à felicidade sólida. Tornando efetiva a relação entre filosofia, sabedoria e felicidade, é preciso pensar naquilo que é verdadeiro, pois somente a verdade torná-la-á firme e duradoura, visto que ela não está pautada no inconsciente. Nesse sentido, o essencial é ser verdadeiro consigo mesmo (não mentir, não tentar enganar-se), a fim de que tenha um verdadeiro e sincero caminho de busca pela sabedoria, pela felicidade verdadeira. Por isso, é proposto pelo autor um caminho perpassado em três tempos, os quais ele exporá em sua obra. Esclarece Sponville (2001, p. 9-10) sobre os três tempos:

Num primeiro tempo, tentarei compreender por que não somos felizes, ou tão pouco, ou tão mal, ou tão raramente: é o que chamarei de a felicidade malograda, ou as armadilhas da esperança. Num segundo tempo, a fim de tentar sair dessa armadilha, exporei uma crítica da esperança, desembocando no que chamarei de a felicidade em ato. Enfim, num terceiro tempo, que poderia se chamar a felicidade desesperadamente, terminarei evocando o que poderia ser uma sabedoria do desespero, num sentido que especificarei e que seria também uma sabedoria da felicidade, da ação e do amor.

O primeiro tempo é caracterizado inicialmente pelo questionamento sobre o que é necessário para ser feliz. Para chegar à resposta de tal questionamento, Sponville aponta para a necessidade de filosofar, a fim de buscar a felicidade e não morrer sem tê-la conseguido satisfatoriamente. Nem todo sábio é feliz de verdade, pelo menos não no sentido em que os estoicos pregam (feliz perante qualquer adversidade humana que os assole, inclusive morte de um ente querido ou amputação de um membro; essa felicidade Sponville não almeja e não a deseja para quaisquer). Ora, segundo Comte-Sponville, para aqueles que supostamente têm tudo para ser feliz, mas não o são, falta-Ihes a sabedoria para o serem de fato. Esta sabedoria é a sabedoria do saber viver; saber viver bem cada dia, cada momento da vida e procurar enfrentar cada adversidade surgida no decorrer da vida, da melhor maneira possível, quando possível; isto é, falta-lhes aprender a viver.

Partindo do pressuposto de que é inerente ao ser humano a busca pela felicidade, sabe-se que este a buscará até encontrá-la. Até mesmo sobre aqueles que tiram a própria vida pode-se dizer que o fazem buscando a felicidade, pois se alguém tira a própria vida o faz porque não está suportando determinada coisa em sua vida ou porque determinado fardo 
é demasiado pesado. É a última e desesperada tentativa de encontrar a felicidade, afastando-se por completo da infelicidade. Quando se tem o que se deseja, pode-se dizer que se é feliz, ao passo que, enquanto não se tem, é-se infeliz. Aquele indivíduo que tira a própria vida o faz porque a sua falta da felicidade o faz sofrer e, portanto, quer fugir de tal sofrimento.

Até que o indivíduo possa considerar-se feliz, ocorre-lhe o impasse entre a felicidade esperada e a felicidade em ato, entre expectativa e desapontamento. Em determinado momento, a pessoa busca obter algo que a fará feliz, depois já não está mais feliz com aquilo que conquistou e novamente busca algo que a fará feliz. É angustiante. Contudo, antes de chegar ao tédio e a uma nova busca por outro bem, Sponville aponta para a existência do prazer e da alegria. Estes existem quando se deseja aquilo que se tem, quando se deseja aquilo que não falta, contudo tais sensações não são duradouras, mas temporárias.

Assim, para Sponville (2001, p. 26), a felicidade é desespero. Não no sentido negativo e mais corriqueiro do termo, mas, segundo o próprio filósofo, no sentido ipsis litteris ${ }^{22}$ do termo, isto é, a felicidade é a falta de esperança, ou ainda, "inesperança”. Em outras palavras, quando o indivíduo está desesperado, no sentido em que Sponville emprega (sem esperança), ele não sofre esperando obter aquilo que ainda não possui, procurando conquistar aquilo que ainda lhe falta, e por isso pode-se dizer que tal indivíduo é feliz, ou até mesmo o próprio pode-se considerar uma pessoa feliz. É, portanto, necessário estar desesperado - sem esperança - para ser feliz. Sponville (2001, p. 26), relendo Spinoza e Nietzsche, acredita que:

[...] é necessário perdê-la, o que é quase sempre doloroso. [...] Um esforço, dizia Spinoza, para nos tornar menos dependentes da esperança... Portanto o desespero, no sentido em que emprego a palavra, não é a tristeza, menos ainda o niilismo ${ }^{23}$, a renúncia ou a resignação: é antes o que eu chamaria de um gaio desespero, um pouco no mesmo sentido em que Nietzsche falava do gaio saber. Seria o desespero do sábio: seria a sabedoria do desespero.

\footnotetext{
${ }^{22}$ Expressão latina que significa "pelas mesmas letras", isto é, tal e qual.

${ }^{23}$ Sobre o niilismo, diz Pecoraro (2007, p. 8): "O termo niilismo deriva do latim nihil, nada. Essa origem revela um primeiro sentido do conceito, que remete a um pensamento fascinado e obcecado pelo nada.
} 
Portanto vê-se que o indivíduo que deseja ser feliz procura adquirir algo ou conquistar determinado bem para ser feliz. Contudo a felicidade baseada nesses alicerces é efêmera. É necessário lançar mão da busca pela sabedoria (adquirida pela filosofia) a fim de conquistar a felicidade duradoura. Existe, porém, algo que atrapalha a jornada daquele que está em tal processo de busca pela felicidade, que é a esperança, ou seja, esperar conseguir aquilo que ainda não possui. Para tanto, Sponville (2001), em sua obra, aponta para o caminho do desespero, ou seja, para o caminho em que se espera e se deseja apenas aquilo que já se possui, evitando, dessa forma, o sofrimento causado pela expectativa.

\section{CONSIDERAÇÕES}

Ao refletir sobre a felicidade neste trabalho, buscou-se compreender em que consiste ser feliz e o modo como alcançar este objetivo. Tendo como intuito ampliar o horizonte, buscou-se entender a visão de felicidade para o cristianismo, por meio de Santo Agostinho (séc. IV), e, logo após, dando um salto no tempo, como a felicidade é compreendida por dois filósofos do século XX: o judeu Viktor Frankl e também o "ateu" André Sponville.

A felicidade é a posse de Deus, segundo Agostinho. Ora, possuir Deus parece ser impossível, visto que Ele é um ser livre de toda e qualquer adversidade temporal e do espaço. Possui-Lo somente é possível em vida - terrestre - por meio da esperança de que um dia - após a morte do corpo material - se contemplará a face de Deus. Nessa perspectiva, apenas é possível ser feliz plenamente após a morte, pois, com tal acontecimento, o homem não ficará mais limitado às questões materiais e temporais, mas estará liberto de todas elas e, portanto, será possível aproximar-se d’Ele.

Sincrônico a isso, em outra abordagem é possível perceber que o sentido deve ser o cerne da busca de qualquer pessoa pela felicidade. Frankl não chegou vivo até o dia da libertação apenas tendo a sorte a seu favor, ou ainda por conta de sua formação acadêmica. Foi preciso tomar para si a responsabilidade da sua própria vida e firmar o propósito de não desistir dela, mediante quaisquer situações que pudessem ser contornadas. Além disso, a libertação psicológica, adquirida após o episódio da visão de sua 
esposa, fez com que Frankl suportasse toda aquela situação de maneira um pouco mais amena.

Nesse sentido, a adesão pelo desespero, quando empregado no sentido defendido por Sponville, também proporciona ao indivíduo uma maneira de ser feliz. Ora, se esse não sofre pela falta daquilo que ainda não possui, pode-se dizer que ele é uma pessoa feliz, ou pelo menos é feliz enquanto não esperar por aquilo que não possui, isto é, feliz porque não sofre. Em contrapartida, também é possível àquele que é feliz desejar o que já possui, como a pessoa que deseja gozar de boa saúde e já goza dela.

Buscar a felicidade, seja ela passageira, seja ela duradoura, ao ponto de quase persegui-la, é contraproducente para o devido fim. A eficácia está centrada em algo um pouco mais profundo, que é a busca pelo sentido. Para tanto, ainda se faz necessário lançar mão da sabedoria, isto é, por meio do raciocínio procurar identificar as vantagens e desvantagens de cada ação e de cada situação. Durante essa vida, ainda fazendo uso da sabedoria, não se sofrerá por demasiado perante as adversidades. Dessa forma, sendo sábio, encontrar-se-á o sentido da verdadeira e duradoura felicidade, tendo sempre consciência de que apenas pos-mortem ela lhe será revelada em plenitude.

Como já dito, a felicidade é um bem quisto a todo ser humano e por cada um buscada. O presente artigo visa contribuir para que cada membro do ambiente acadêmico e da sociedade em geral possa identificar um possível norte rumo ao encontro dessa felicidade verdadeira e duradoura. Pode-se dizer que o sentido, encontrado após ter o indivíduo lançado mão da sabedoria, é a chave-mestra que possibilita para o homem contemporâneo identificar o que ele deve fazer para viver feliz nessa vida, enquanto aguarda a vivência da felicidade plena após sua morte. Por isso, também é possível dizer que a morte não é algo a ser temido para aquele que soube encontrar o sentido de cada situação vivida, o sentido da própria vida, pois tal pessoa saberá que, ao dar o último suspiro, será mais feliz do que foi em vida, será feliz plenamente.

\section{REFERÊNCIAS}

AGOSTINHO, Santo. Soliloquia. Tradução de Adaury Fiorotti. São Paulo: Paulus, 1998a. (Coleção Patrística). 
AGOSTINHO, Santo. De beata vita. Tradução de Nair de Assis Oliveira. São Paulo: Paulus, 1998b. (Coleção Patrística).

AUDINO, Tatiana Fagundes. O imperativo da felicidade na contemporaneidade. 2015. Dissertação (Mestrado em Teoria Psicanalítica) - Universidade Federal do Rio de Janeiro, Rio de Janeiro, 2015. Disponível em: http://teopsic.psicologia.ufrj. br/arquivos/documentos/2105E949B472D3E4924701956D109B14.pdf. Acesso em: 17 maio 2019.

CEBRID. Ansiolíticos ou tranquilizantes? São Paulo: Unifesp, [s.d.]. Disponível em: https://www2.unifesp.br/dpsicobio/cebrid/quest_drogas/ansioliticos.htm. Acesso em: 26 abr. 2019.

CORREIA, Joana Paula Pereira. Maniqueísmo: religião, seita ou heresia? In: SIMPÓSIO NACIONAL DE HISTÓRIA, 17., 2013, Natal, RN. Anais [...]. Natal/RN: Anpuh Brasil, 2013. Disponível em: http://www.snh2013.anpuh.org/resources/ anais/27/1371264028_ARQUIVO_ArtigoAnpuhNatal.pdf. Acesso em: 21 maio 2019.

COSTA, Eduardo. Waffen-SS: a tropa de elite de Hitler. 2013. Monografia (Graduação em História) - Universidade Federal de Santa Catarina, Florianópolis, 2013. Disponível em: https://core.ac.uk/download/pdf/30399227.pdf. Acesso em: 5 maio 2019.

FRANKL, Viktor Emil. Em busca de sentido: um psicólogo no campo de concentração. Tradução de Walter O. Schlupp e Carlos C. Aveline. Porto Alegre, RS: Sulina, 1987.

FRANKL, Viktor Emil; LAPIDE, Pinchas. A busca de Deus e questionamentos sobre o sentido. Tradução de Márcia Neumann. Petrópolis, RJ: Vozes, 2014.

PECORARO, Rossano. Niilismo. Rio de Janeiro: Jorge Zahar, 2007.

SPONVILLE, André. Apresentação da filosofia. Tradução de Eduardo Brandão. São Paulo: Martins Fontes, 2002. Disponível em: http://abdet.com.br/site/wp-content/ uploads/2014/10/Apresentação-da-Filosofia.pdf. Acesso em: 22 abr. 2018.

SPONVILLE, André. A felicidade, desesperadamente. Tradução de Eduardo Brandão. São Paulo: Martins Fontes, 2001. Disponível em: http://abdet.com.br/site/wpcontent/uploads/2014/10/A-Felicidade-Desesperadamente.pdf. Acesso em: 22 out. 2018. 
